\title{
TRADITIONAL PROFESSION AND LIVELIHOOD STRATEGIES OF BEDE COMMUNITY IN BANGLADESH: A SOCIOLOGICAL STUDY
}

\author{
Ayesha Siddequa Daize ${ }^{1}$ \\ Mst. Laboni Akter Lima ${ }^{2}$
}

\begin{abstract}
Bede community is a racial ethnic minority and floating people in Bangladesh. They move from one place to another to carry out their business for earning. After hearing the term Bede, the things which first clicked in one's mind is that women roaming in a village with bag of business products on their head and vociferating to attract people to whom they offer treatments (joint pain, toothache), sell products like, home utensils, trinket sand amulets, bangles, herbal medicines etc. They are member of an ethnic minority group with unique traditional culture and lifestyle and their behavioural pattern also has a distinctive character, unusual from the people of mainstream society. Generally, these groups of people are socially, economically, and politically excluded and they are severely deprived of all types of necessities. Often, they become victim of discrimination and racial violence and obviously they are the subject of human rights violations. In this paper, the researchers attempt to draw the traditional nature of livelihood pattern of Bede community of Bangladesh, their exclusion and vulnerable socio-economic status, their adaptability power with the worst situation. Furthermore, this paper states some recommendations towards government and NGO's for giving legal and voluntary actions to ensure the rights of Bede people in Bangladesh that may impact to their holistic development.
\end{abstract}

Keywords: Living Patterns, Nomadic, Bede Community, Vulnerability, Exclusion.

\footnotetext{
1 Ayesha Siddequa Daize, PhD is Associate Professor, Department of Sociology, Jagannath University, Dhaka-1000, Bangladesh. Email: daisydaisydu@yahoo.com [Corresponding Author]

2 Mst. Laboni Akter Lima is MSS Student, Department of Sociology, Jagannath University, Dhaka-1000, Bangladesh.
}

Social Science Review [The Dhaka University Studies, Part-D], Vol. 38, No. 1, June 2021 DOI: https://doi.org/10.3329/ssr.v38i1.56527 


\section{Introduction}

Cultural and ethnic diversity has moulded a number of distinctive communities in Bangladesh. Among them the Bede people, known as the River Gypsy, are the only major nomadic community live scattered in different parts of the country. Bede is a marginalized Muslim community in Bangladesh (Arefeen, 1992). The Bede people are well known for their nomadic lifestyle and unique socio-cultural way of life. Usually, they show snake charming, monkey show, and have esoteric knowledge of magical healing. Despite being Muslim, they believe in a number of gods and goddesses, mainly snake goddess. The Bedes have their own language and different culture than the other ethnic groups in Bangladesh. But this traditional scenario has undergone significant changes over the past decades (Das, 2013). The customs of Bede community are threatened by the development of modern science and technology. Consequently, their small business of selling elixirs, amulets, and trinkets is not further attracting people and people are not entertained by their antic anymore. These are making them peripheral and struggling to preserve their customs and heritage. Certainly, Bede Culture has uniqueness, so preservation of their culture like other ethnic communities will add the diversity in multicultural country like Bangladesh (Rahman, 2016). They tried to shift their own income pattern from traditional to mainstream economic activities for survival. But they were struggling to save their own customs and culture which they were inherited from their previous generation in thousands of years. Many government and non-government organizations were come forward to establish them in the mainstream of the society but due to lack of facilities hinders the implementations (Shawon \& Rabbi, 2017). As they are a minority group, encompassed with various socio-economic problems and vulnerability and they are also excluded from social, economic, and political rights. Due to rapid social change, they are now losing their tradition and gypsy culture. So, it is necessary to establish them into mainstream society through overcoming their socio-economic problems and preserving their culture that ultimately led our national development. This study intends to find out the actual status of Bede community as racial ethnic minority group in Bangladesh and recommend some guidelines to develop an easy and effective mechanism for provision of basic rights and services for their improvement. 


\section{Background of the Bede community}

Edward Dalton mentions in his famous publication (1978) Beday as a gypsy-like tribes. The term Bede and defends their Arab origin based on similarity with the Arab Bedouin. Although the Banglapedia mentioned them as descendants of the Montong tribe of Myanmar. Bedes are engaged in the snake charming, catching of snakes, curing snake's bites, traditional and spiritual healing services, magic show, and monkey show, selling of bangles and trinkets (Maksud, 2002). Around 17 lacs Bede live in Bangladesh, they live 53 districts in Bangladesh. That group of people came in the Indian subcontinent, due to their illiteracy, they show the animal game was their main occupation for survival. Then they came to Bangladesh (Indian subcontinent) through river by boat and stopped their boat on the bank of Bangshi river and started living on the boat. The bank of Bangshi river was occupied by Hindu Jamider in that period. Bede people started working under the Hindu Jamider and settled down gradually. Many of them lived in Assam, Meghalaya, Calcutta, Siliguri, Gua, and Nadia in India. Almost nearly 200 years a large number of Bede people have been living near the bank of the Bangshi river in Savar. The Savar Bede Palli includes three villages Kanchanpur, Amorpur and Porabari, around 15-16 thousand Bede people live there. Around 32 families, total population 150, live at Tarabo beside Bishwaroad in Narayanganj. They have started living in Tarabo for 25 years ago. The peoples in their community also live at Mirer bazaar, Shrinagar in Gazipur (around 400 Bede family live there), Sunamganj, Sylhet, Manikchari (Chittagong), Chittagong, Munshiganj districts of Bangladesh.

\section{Objectives of the Study}

The study will take the following as the objectives: a) to understand the nature of traditional livelihood pattern and economic activities of Bede community; b) to find out socio-cultural background and practices of Bede community; c) to find out the causes of their exclusion and discrimination from normal livelihood pattern of mainstream society; and d) to find out the possible recommendation from respondents to attain the expected and developed situation of Bede community.

\section{The Social Exclusion Framework}

The Social exclusion framework has been used to explain socio- economic exclusion and vulnerable position of the Bede community in urban contexts. As a 
definition, "Social exclusion reflects the multiple and overlapping nature of the disadvantages experienced by certain groups and categories of the population, with social identity as the central axis of their exclusion" (Kabeer, 2006). Social exclusion can therefore be explained in terms of group interactions aimed at maximizing value and minimizing costs. Individuals are most vulnerable when they have fewest personal capacities and material resources but none of these threatens their survival so long as they enjoy the protections afforded by membership of an inclusive group that co-operates productively and redistributes its product (Jordan, 1996). Social Exclusion is mainly a group concept, Amartya Sen said that the situation were some people are kept out, and where some people are being included and describes two situations as unfavourable exclusion and unfavourable inclusion. The acts of exclusion which excludes people from having an access and entitlement to certain social groups that are based on the recognized and accepted principles, rules, norms, practices of fairness can be considered as unfair exclusion, similarly the inclusions which provide access and entitlement to persons from certain social groups but on different terms and conditions can be termed as unfair inclusion (Sen, 2000). So, social exclusion concept is central in this study, and it provides a useful framework for analysing the present situation of Bede people in Bangladesh in relation to their racial ethnic minority-based exclusion, discrimination, and vulnerability.

\section{Methodology}

To analyse the critical position of Bede community in our society, the study has followed a triangulation method i.e., a combination of quantitative and qualitative research method. To discuss this issue, we have used questionnaire survey, through in-depth interview, non-participant observation and case study method to collect data. In-depth interviews based on semi-structured interview guide helped us to explore the personal and social experiences, opinions, and feelings of the interviewees. To bring out flexibility in the data collection, both scheduled and unscheduled questionnaires were used. In this study, 60 respondents had been selected as a target population from 16000 study population who aged from (1590) years old. There were around twenty-five thousand families, including (Savar, Rampura, Tarabo). Random sampling in this study was selected due to shortage of time and long distance of study areas. Ten case studies were also conducted from three research sides which were also based on purposive sampling. The study was conducted in three areas including Savar, Rampura and 
Tarabo at Dhaka and Narayanganj City in Bangladesh. The study area consists near about sixteen thousand populations. The study conducted at Porabari, Amorpur and Kanconpur villages at Savar (these three villages jointly called the Bedepalli at Savar), a slum behind the East West University at Rampura and another slum at Tarabo in Narayanganj City. Respondents were selected from those three areas including Savar (Porabari, Amorpur, Kanconpur), Rampura and Taraboin Dhaka and Narayanganj City. Data were transcribed and analysed with the help of The SPSS (Statistical Package of Social Sciences, version 22) to get the target statistics and interpretation.

\section{Data Findings \& Analysis}

\section{Socio-demographic Profile of the Respondents}

The present study was conducted among the Bede peoples of three Bede villages at Savar, Rampura and Tarabo in Dhaka and Narayanganj City. In total 60 respondents ranging from age 10 to $80+$ years were interviewed. Of them 51.7 percent were female and 48.3 percent were male, married 90 percent. The Table 1 shows that the age groups of the respondents where it is clear that many respondents, 36.7 percent belong to the age group (31-40); while 30 percent is under the age group (21-30); besides, 11.7 percent of the total respondents belong under (51-60) age group. Moreover, the age group (10-20) and (41-50) consist approximately each 6.7 percent of the total respondents. Meanwhile the age group (61-70) and (80+) consist of about 3.3 percent respondents and rests of the 1.7 percent respondents are from the age group (71-80). So, the table demonstrates that mean age group of the respondents is 22.5 years.

Table 1: Various age groups of the respondents

\begin{tabular}{|c|c|c|}
\hline Age (in year) & Frequency & Percentage \\
\hline $11-20$ & 4 & 6.7 \\
\hline $21-30$ & 18 & 30.0 \\
\hline $31-40$ & 22 & 36.7 \\
\hline $41-50$ & 4 & 6.7 \\
\hline $51-60$ & 7 & 11.7 \\
\hline
\end{tabular}




\begin{tabular}{|c|c|c|}
\hline $61-70$ & 2 & 3.3 \\
\hline $71-80$ & 1 & 1.7 \\
\hline $80+$ & 2 & 3.3 \\
\hline Total & $\mathbf{6 0}$ & $\mathbf{1 0 0 . 0}$ \\
\hline Mean & $\mathbf{2 2 . 5}$ & \\
\hline
\end{tabular}

Source: Field survey 2020

The study indicates that 51.7 percent respondents are female. On the other hand, 48.3 percent respondents are male. The findings of the religious status of the respondents reveal that all the respondents (100 percent) are Muslims. Respondent's marital status shows that the largest numbers of the respondents 90 percent are married. While, about 5 percent of the respondents are unmarried; 3.3 percent respondents are the divorced and 1.7 percent of the total respondents are widow. The table signifies that a large number of respondents are illiterate 76.7 percent; from them some can hardly write their name only. Again, about 20 percent of the respondents have understood primary education (I-V). Meanwhile, near about each 1.7 percent of the total respondents have completed their secondary and higher secondary education. It may be due to their previous nomadic life, lack of consciousness, poor education facilities or economic hardship.

\section{Present Economic Activities of the Respondent}

Income \& expenditure pattern

In social science literature, there is general agreement on the core features of social exclusion, its principal indicators and the way it relates to poverty, discrimination, inequality, and vulnerability. In a study Amin said that bedeys in Bangladesh are poverty stricken. Their incomes vary from place to place and time to time. They have no access to meet their basic needs and even are vulnerable, destitute or in Marxian term proletariat. They belong to one of the professional minority income groups of Bangladesh having a very low range of average income (Amin, 2015). The Table 2 indicates that a significant number (50\%) of the respondent's monthly income is Tk. (5001 to 10000). While monthly incomes of 28.3 percent respondents are between Tk.10001 to15000. On the other hand, 8.3 percent respondents mentioned their monthly family income is Tk. up to 
5000). Another 6.7 percent respondent's monthly income is between Tk. 20001 to 25000 and rests of the 1.7 percent of the respondent's monthly income respectively Tk. (15001 to 20000), (25001 to 30000), (30001 to 35000) and (35000\& above).

Table 2: Monthly income of the respondents

\begin{tabular}{|c|c|c|}
\hline $\begin{array}{c}\text { Monthly family } \\
\text { income }\end{array}$ & Frequency & Percentage \\
\hline Up to 5000 & 5 & 8.3 \\
\hline 5001 to 10000 & 30 & 50.0 \\
\hline 10001 to 15000 & 17 & 28.3 \\
\hline 15001 to 20000 & 4 & 1.7 \\
\hline 20001 to 25000 & 1 & 6.7 \\
\hline 25001 to 30000 & 1 & 1.7 \\
\hline 30001 to 35000 & 1 & 1.7 \\
\hline $35001 \&$ above & $\mathbf{6 0}$ & 1.7 \\
\hline Total & 100.0 \\
\hline
\end{tabular}

Source: Field survey 2020

The findings of the table 2 reflect that most of the respondents are under low income generating socio-economic circumstances. It may be due to low level of literacy rate, lack of professional diversities and skill, lack popularity of their usual professions. The findings of the monthly expenditure of the respondents showed that a significant number (46.7\%) of the respondent's monthly expenditure is between Tk. (5001 to 10000). While 33.3 percent of the total respondent's monthly expenditure is Tk. 10001 to 15000 . Again, 8.3 percent of the respondent's monthly expenditure is between Tk. Up to 5000. On the other hand, rests each 1.7 percent of the respondent's monthly expenditure respectively is between Tk. (25001 to 30000), (30001 to 35000) \& (35000 \& above). 
Figure 1: Family shortcoming of the respondents $(n=60)$

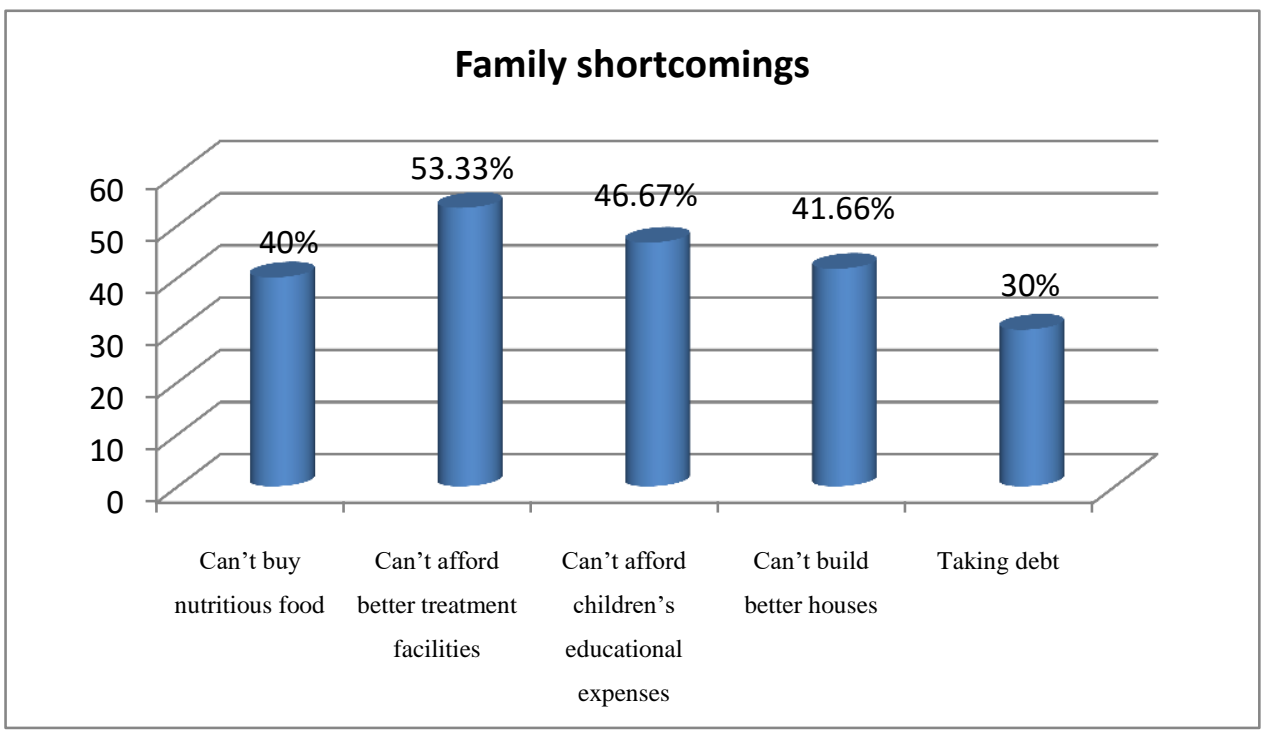

Source: Field survey 2020

Figure 1 indicates that a significant number, 41.66 percent of the respondents cannot build better houses; while each 46.67 percent of the respondents, respectively cannot afford their children's educational expenses and 53.33 percent cannot effort better treatment facilities. On the other hand, 40 percent respondents cannot buy nutritious food for their family members and again 30 percent respondents take debt from moneyed persons of their community and non-governmental organizations.

\section{Consumption pattern}

Rice and vegetable are consumed daily by all but foods with higher protein content are consumed daily by less than 20 percent. Meals are consumed three times per day in 94 percent of families. When asked: Do you feel that your family eats a balanced diet and receives proper nutrition? 84 percent respond negatively. Subjects are asked if they or their family ever go hungry; 64 percent sometimes response and 36 percent say never. According to respondents, children are provided with three meals in a day. But inadequate quality and lack of diversity of food are matters of concern in food habit. 
Table 3: Average food intake per person per day

\begin{tabular}{lcc}
\hline \multicolumn{1}{c}{ Food items } & $\begin{array}{c}\text { Average intake } \\
\text { (in grams) }\end{array}$ & $\begin{array}{c}\text { Standard deviation } \\
\text { (in grams) }\end{array}$ \\
\hline Rice & 401.37 & 123.02 \\
\hline Cereals & 23.30 & 43.02 \\
\hline Lentils & 20.95 & 17.17 \\
\hline Potatoes & 129.19 & 65.61 \\
\hline Vegetables & 118.81 & 73.44 \\
\hline Fish & 34.07 & 33.34 \\
\hline Edible oil & 19.55 & 11.47 \\
\hline Meat and poultry & 17.90 & 22.76 \\
\hline Milk and milk power & 25.59 & 43.73 \\
\hline Fruit & 7.23 & 18.0 \\
\hline
\end{tabular}

Source: Field survey 2020 [The recall method is used to measure household consumption. The total amount of consumption of the week before the interview was recorded and then per capita consumption per day was calculated.]

Table 3 shows that the average rice intake per person is slightly above 400 grams per day and there is a wide variation (std. dev. 123.02) in rice intake among them. The bad, mostly consume rice and few of them eat cereals at breakfast. With rice they mainly eat lentils, potatoes, and vegetables, as these items are relatively cheap. The average intake of lentils, potatoes and vegetables is 20.95, 129.19 and 118.81 grams per person per day respectively but there are wide differences in the rates of consumption of these items, which are expressed by standard deviations. Most of the Bede consume fish, but they consume only a very small quantity (average $34.07 \mathrm{gram}$ ). These Bede people usually buy a poor quality of fish from local fish markets at low prices. The average intake of expensive items like meat and poultry, milk and milk powder and fruit are 17.9, 25.59 and 7.23 grams per person per day, respectively. The table also shows wide deviations in intake of those expensive items too. The Bede mostly avoids those expensive items due to their low incomes. Their consumption pattern is expressly though the following comments. 45 years old a woman commented: 
I have four kids, among them two are going to school in a different class. My husband is selling medicine of joint pain. We earn together money sufficiently, but my husband does not give me a single take to maintain family expenditure. He finishes his whole money to buy alcohol and other bad habits. So, it becomes too tough for me to maintain family budget. We just live on basic food, rice, dal (lentils), potato and other vegetable. So, it is not possible for me to buy any expensive item, like meat, milk or fruits and it becomes a dream for my family to buy meat or big fish. Sometimes, I buy small fish which quality is not good. We can eat meat one or two times only in a year. My little 3 years old daughter prefers to drink milk but it is not possible for me to buy this expensive item (Case study -1).

\section{Nature of their work}

The Bedes are among the poorest groups of Bangladesh, and they typically earn their living as fishermen, snake charmers, divers for river oyster pearls, traditional medicine and talisman sellers, and practice of black magic through which they claim to cure people or fulfil the wishes of their clients. The women folk among the Bedes usually sell trinkets and jewellery items among the rural women. Their other profession includes curing carious teeth and applying the shinga (Shinga is a buffalo horn or horn obtained from oxen, which the Bede women utilizes to draw blood from a sick patient, where the Bede women judges that blood needs to be withdrawn to cure the sickness) (Hossain, Miajee, Khatun, \& Rahmatullah, 2010). But day by day, they lost the opportunity of their traditional profession. As the result, many Bede are seen begging in the bus stands or busy streets in different part of Bangladesh.

Table 4: Current occupations of the respondents $(n=60)$

\begin{tabular}{lcc}
\hline \multicolumn{1}{c}{ Name of occupations } & Frequency & Percentage \\
Snake charming & 5 & 8.33 \\
Shinga lagano & 7 & 11.67 \\
Selling herbal medicine & 11 & 18.33 \\
Sell amulets and trinkets & 8 & 13.33 \\
Small business & 9 & 15 \\
Service & 5 & 8.33 \\
\hline
\end{tabular}




\begin{tabular}{lcc}
\hline Animal husbandry & 4 & 6.67 \\
No work & 5 & 8.33 \\
Others & 6 & 10 \\
Total & $\mathbf{6 0}$ & $\mathbf{1 0 0}$ \\
\hline
\end{tabular}

Source: Field survey 2020

The findings of the study indicate that a particular number of the respondents are small businessmen that are 15 percent. About 11.67 percent respondent's occupation is Shinga business and women are mostly related to this Shinga business, while 13.33 percent of the respondents sell amulets and trinkets as their occupation. Then each 18.33 percent of respondents, respectively sell medicine of various herbal plants, occupation related to Jharfuk and sell medicine of joint pain. On the other hand, 8.33 percent respondent's occupation is snake charming and men are mostly related to snake charming as their occupation and another each 8.33 percent of respondents respectively are engaged with government and non-government services and showing magic. On the other hand, 15 percent respondents have tea stalls and other small business by which they earn money for their family maintenance. Another 6.67 percent respondent's occupation is related to snake selling or snake renting, they catch snakes and sell those snakes or rent those snakes for money. Respondent of 10 percent is engaged in other different types of work and rest, of the 8.33 percent have no work.

\section{Physical environment of Bede polli}

Bede peoples suffered from various problems like lower house structure, lack of pure drinking water, water logging, mosquito, and others. Sanitation problem was faced by 22.8 percent respondents. While around 46.67 percent respondents have lower house structure, their lower house structure enhanced sufferings in case of storm (kal baishakhi jhar). Again, 18.3 percent respondents illustrated that they do not get pure drinking water. On the other hand, each 9.4 percent respondents respectively exposed that they suffered from electricity problem and mosquito problem. And again, 9.4 percent respondents face water logging which caused by excessive rain and low land area. And finally, 2.8 percent respondents claim that they could not get opportunities to catch snakes, forest ministry declare that no one can catch snakes because of preserving the animal environment. If they cannot snake catching opportunities, they claimed alternative employment opportunities from the government of Bangladesh. But snake catching was their 
traditional occupation; they wanted to preserve their traditions and 9.4 percent respondents have no problem due to their standard of living and economic solvency. People living in Tarabo face acute sanitation problem, lack of pure drinking water, having no gas line etc.

\section{Traditional Livelihood Pattern of the Respondents}

Bedes have some skills, which are related to traditional healing services, entertainment services, petty trading etc. but now-a-days, their traditional services and products are losing market demand (Sarkara,.Rahmanb,\& Saha, 2013). Now-a-days, the educated and sceptical modern people hardly believe in their spiritual healing service (Islam, 2018). The study shows that 45 percent respondent leaving their previous traditional occupations and 55 percent hold their traditional occupation to maintain their livelihood.

Table 5: Main reasons behind quitting previous occupations of the respondents

\begin{tabular}{ccc}
\hline Change previous occupation & Frequency & Percentage \\
Yes & 27 & 45 \\
No & 33 & 55 \\
Reasons behind Quitting previous & & \\
occupation & 11 & 40.74 \\
Forced for maintaining livelihood & 5 & 18.52 \\
Rapid urbanization & 3 & 11.11 \\
Loss of professional popularity and & 4 & 14.81 \\
credibility & 2 & 7.41 \\
Expansion of education \& consciousness & 2 & 7.41 \\
For removing social stigma & & \\
Others & & \\
Total & 27 & $\mathbf{1 0 0 . 0}$ \\
\hline
\end{tabular}

Source: Field survey 2020

The table 5 shows that several reasons worked behind leaving their previous traditional occupations. Among them, about 40.74 percent of the respondents claim that they left their traditional occupations because of forced for maintaining 
livelihood. Then 18.52 percent respondents ensure that they left their traditional occupation due to rapid urbanization. On the other hands, 14.81 percent respondents claim the expansion of education and increasing consciousness as reason and again each 11.11 percent of the respondent's assert loss of professional popularity and invention of advanced medical facilities as reasons. While 7.41 percent respondents left their traditional occupations due to removing social stigma and 7.41 percent respondents assert for other reasons.

\section{Satisfaction with traditional livelihood pattern}

The parental part of our society behaves on a way that they have to eliminate it from society. They are on the verge of extinction. Beside poverty and desperate attempt for survival force them to shift from their traditional occupation to conventional. If this situation is continuing over period of time, like the impact of biodiversity loss, our society will experience the lack of Bede culture. Also, our next generation will have no concept about Bede ((Amin, 2015). So, the new generation of Bede community now do not want to live in a boat, they want modern facilities. Bede children are wanted to grow up like the children of the mainstream society.

Table 6: Main reasons behind not to see their children in traditional occupations of the respondents $(n=49)$

\begin{tabular}{|c|c|c|}
\hline Reasons & Frequency & Percentage \\
\hline For better life & 17 & 34.70 \\
\hline Losing demand of traditional occupations & 8 & 16.33 \\
\hline For adjustment to changing society & 9 & 18.37 \\
\hline The income of the traditional occupations is low & 5 & 10.20 \\
\hline Free from social stigma & 6 & 12.24 \\
\hline Others & 4 & 8.2 \\
\hline Total & $\mathbf{4 9}$ & $\mathbf{1 0 0 . 0}$ \\
\hline
\end{tabular}

Source: Field survey 2020

In present study data shows that a significant number $(81.67 \%)$ of the total respondent's state that they want not to see their children in their traditional occupations and rests 18.33 percent affirm that they want to see their children in 
their traditional occupations due to several reasons. The table 6 shows that a significant number of respondents (34.70\%) said that for ensuring a better life of their children as reason of not to see them in traditional occupations and 16.33 percent respondent said that they are losing demand of traditional occupations due to lack of herbal plants, advancement of medical treatment facilities, river drying, imposed restrictions of catching snakes, people's consciousness etc. and 10.20 percent respondent said their traditional occupations income is very low. Meanwhile, 18.37 percent respondents supposed that due to adjustment with changing society, the occupations of their children need to be changed, otherwise they left behind to the mainstream society like them. Then 12.24 percent respondents affirmed that career change works as the medium of their children to free from the social stigma of being Bede and rests 8.2 percent respondents explained other reasons.

Table 7: Reasons behind to see their children in traditional occupations of the respondents $(n=11)$

\begin{tabular}{|c|c|c|}
\hline Reasons & Frequency & Percentage \\
\hline Protect clan tradition & 6 & 54.55 \\
\hline The profits are high & 1 & 9.10 \\
\hline Satisfied with their lifestyle & 2 & 18.18 \\
\hline Opportunities of other professions are low & 2 & 18.18 \\
\hline Total & $\mathbf{1 1}$ & $\mathbf{1 0 0}$ \\
\hline
\end{tabular}

Source: Field survey 2020

The table 7 represents they want to see their children in traditional occupations due to some reasons. Among them 54.55 percent respondents said that they want to protect their clan tradition by children. Then 18.18 percent respondents claimed that due to lack of education, opportunities of other professions are low. On the other hand, 18.18 percent respondents exposed that they are satisfied with their lifestyle and only 9.1 percent respondents claimed high profit of traditional occupations.

\section{Social Structure of the Respondents}

Though everybody acknowledges the cultural diversity and special identity of Bede community, Bede community's recognition as socially excluded and 
absence of official recognition instinctively limits their access from various services and social rights as well as lead a settled life with the mainstream society (Akter \& Kalam, n.d.). The study represents the family type of the respondents, in where 46.7 percent of the total respondent's family types are nuclear, 53.3 percent respondent's family types are extended. Males are the head of their family said by 51.7 percent respondents; females are the head of their family narrated by 20 percent respondents and rests 28.3 percent have both male and female headed families. A major part (55\%) of the total respondents belongs among (3-6) family members and 21.7 percent of the respondents belong between (7-9) family members. Meanwhile, 11.7 percent of the respondents belong among (1-3) family members. Then 6.7 percent of the respondents belong between (14-16) family members and 3.3 percent of the respondents have between (10-13) family members. On the other hand, rests 1.7 percent of the respondents has (16+) family members. Shahinur Islam, the leader of the Savar Bede community (age 61 years) said:

After 2014, we come under the light of development. Before 2014 we were in the darkness, and we are involved in criminal activities. It may be cause for our unconsciousness and illiteracy. Then the peoples of Bede community were involved in the drug business, drugs addiction, theft, robbery, and others law breaking deviant behaviours and just then DIG Habibur Rahman appeared in front of us with light of hope. (Case study 2)

\section{Asses to Health Service}

In previous time Bede people only take Kabiraji ${ }^{3}$, Jharfuk $^{4}$, herbal medicine and domestic treatment but in recent times they go hospitals for treatment due to social change, their permanent settlement and growing consciousness. Primarily in cases of their illness, they get treatment from kabiraj and domestic herbal medicines in case of their illness, but only in case of severity they go to hospitals.

\footnotetext{
${ }^{3}$ Kabiraji practice was based on local medicinal plants or substances of animal origin. Kabiraji practice had both formal and informal aspects: the registered traditional practitioners of Unani and Ayurvedic medicine were also locally termed Kabiraj.

4 Jar-fuk is mostly used as a treatment for diseases in Bangladesh. The bede uses this type of folk treatment from their spiritual leaders to overcome their illnesses.
} 
Table 8: Form of getting treatment in case of illness of the respondents $(\mathbf{n}=60)$

\begin{tabular}{|c|c|c|}
\hline Forms of getting treatment & Frequency & Percentage \\
\hline Medical treatment & 12 & 20 \\
\hline Homeopathy treatment & 10 & 16.67 \\
\hline Kabiraji treatment & 18 & 30 \\
\hline Domestic treatment & 9 & 15 \\
\hline Jharfuk & 11 & 18.33 \\
\hline Total & $\mathbf{6 0}$ & $\mathbf{1 0 0}$ \\
\hline
\end{tabular}

Source: Field survey 2020

The table 8 shows that 20 percent of the total respondents receive medical treatment. About 15 percent respondents elucidate that they usually take domestic treatment in the case of illness, but in case of severity they take patients to hospitals and 30 percent respondents said that they receive Kabiraji treatment. On the other hand, each 18.33 percent respondents respectively take herbal medicine and Jharfuk but rests 16.67 percent respondents take homeopathy treatment in case of illness. So, it is clear that a significant transformation has occurred in their treatment system. The findings of the study are about child vaccination in where 56.7 percent of the total respondents claim that their children received vaccine and 43.3 percent respondents affirmed that their children do not get any vaccine. Though they are an ethnic minority group, they face a social stigma in our society. Majority respondents (55.0\%) of total respondents face no discriminations in hospital in case of getting treatment and only45 percent respondent's give statement are that they face discrimination in hospital due to their social stigma as Bede people.

\section{Asses to Education}

Though everybody acknowledges the cultural diversity of the Bedes and their special identity but absence of official recognition unable them to establish their special needs for education and health and deprives them from establishing their rights as a citizen (Maksud \& Rasul, 2006). A significant number of parents (37.7\%) statements are that their children receive education from specific Bede school. Total 24.5 percent parents ensure that their children go local government 
school and 11.3 percent of them stated their children take education from a local private school. Street schools play a significant role to educate their children Meanwhile, 26.5 percent parents affirmed that their children do not receive an education from any formal educational institutions. Their children also receive education from local Madrasa ${ }^{5}$.

Figure 2: Types of educational intuitions

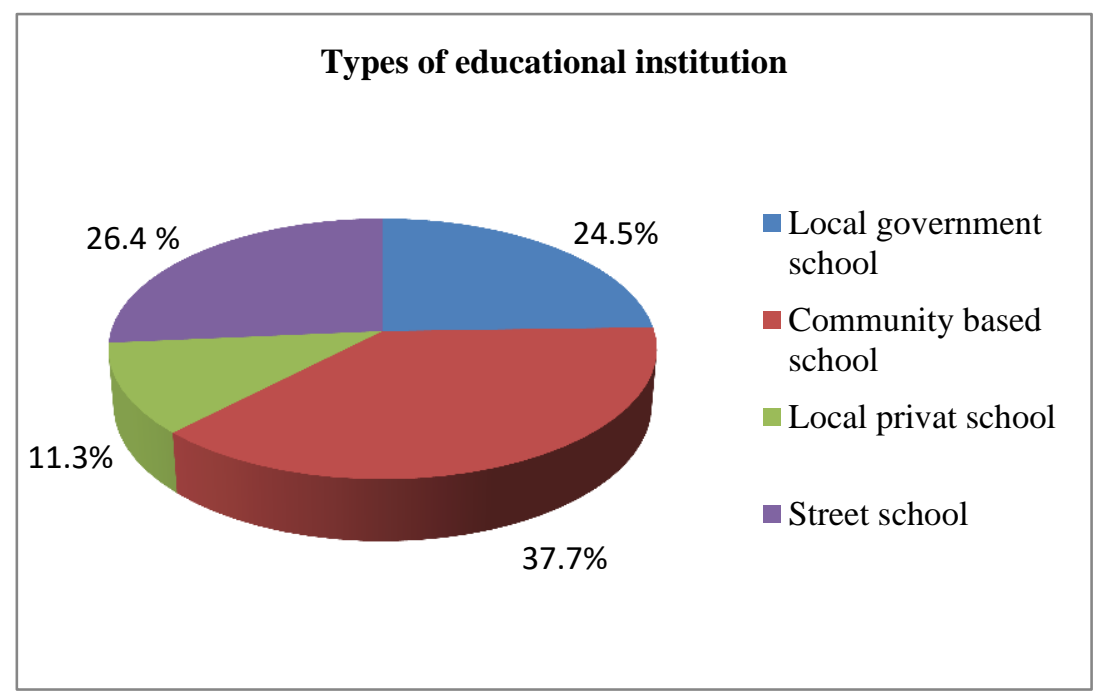

Source: Field survey 2020

A coaching centre named Uttoron shikkhaloy has built at Savar for the children of the Bede community to increase their literacy rate. In where, students from class five to twelve can learn their lessons of all subjects. Sometimes the students of Jahangirnagar University take classes in Uttoron shikkhaloy. A primary school will be built named Habibur Rahman primary school (Bede people prefer this name). Already 1acre land has bought for building that primary school. They got budget from the government for their development. A Bede leader Abdul Kuddus, (60 years old) said:

A girl in our community completed her post-graduation and got her employment in the teaching profession that makes us so proud. She is the idol of all Bede girls in our community and many of them now go to school with such dream of

\footnotetext{
${ }^{5}$ Madrasa is the Arabic word usually refers to a specific type of religious school or college for the study of the religion of Islam, though this may not be the only subject studied.
} 
improvement. Now, we hope for a better life for ourselves and our next generations. We hope our children will have employed themselves as government officer or other respectful professions after completing their education. We do not want to see them as Bede anymore. We spend a miserable life with many hardships, but do not want this type of life for our next generations. (Case study 3)

\section{Social Bondage Within Groups and the Broader Society}

The social acceptance was uncommon due to their living style, very tough traditional and ritual bindings to make relationship with the other out peoples (Shawon \& Rabbi, 2017). But now -a -days for many issues they association with local people. Though Bede community are a minority group, they are integrated with having deep bondage among themselves. Around a major portion (88.3\%) of the total respondents ensured that they maintain good relationship among the peoples in their community.

Table 9: The issues of their main association with local people $(n=60)$

\begin{tabular}{|c|c|c|}
\hline Association with local people & Frequency & Percentage \\
\hline Yes & 55 & 91.7 \\
No & 05 & 8.3 \\
\hline The main causes for association (n=55) & & \\
Money transaction & 8 & 14.55 \\
For employment & 6 & 10.91 \\
For business purpose & 19 & 34.55 \\
Participation in the event & 7 & 12.73 \\
Because of living together & 12 & 21.82 \\
Others & 3 & 5.45 \\
\hline Total & 55 & 100 \\
\hline
\end{tabular}

Source: Field survey 2020

The findings of the study reveal that a major portion (91.7\%) of total respondents affirmed their association with local peoples due to various purposes, but rests 8.3 percent respondents said that they do not associate with local people. Among them, 34.55 percent respondents elucidated that they associate with local peoples 
for business purpose. Meanwhile, 21.82 percent respondents claim that they associate because they live together and another, 14.55 percent transaction of money is a purpose of their association explained by respondents. And again, 10.91 percent respondents associate for employment purpose and rests 5.45 percent respondents associate because local peoples are other purposes.

A woman named Akhikunnesa (56 years old), explained about racial stigmatized on them. She said:

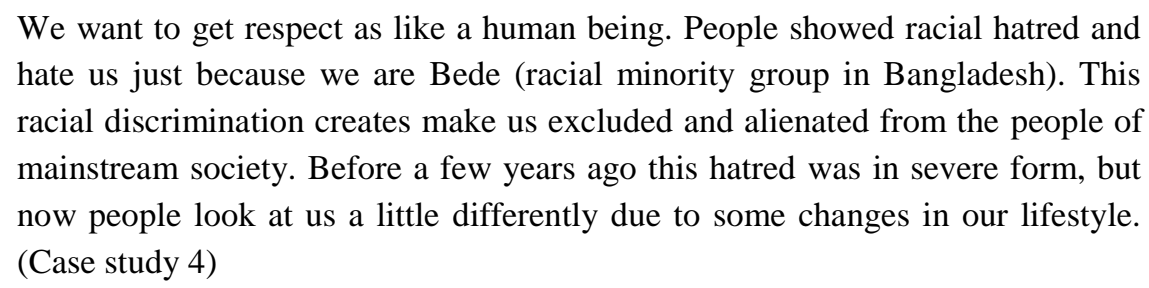

We want to get respect as like a human being. People showed racial hatred and hate us just because we are Bede (racial minority group in Bangladesh). This racial discrimination creates make us excluded and alienated from the people of mainstream society. Before a few years ago this hatred was in severe form, but now people look at us a little differently due to some changes in our lifestyle. (Case study 4)

The study shows that about 56.7 percent respondents said that they have no conflict with local people and rests of the 43.3 percent respondents affirmed that they have little conflict with local peoples. Among them, 64.5 percent respondents ensure that the reason of their conflict with local people is a child. Sometimes children of local people and Bede people quarrel with each other, and their conflicts turn into parental conflicts and 19.4 percent respondents claimed that racial hatred as reason and 9.7 percent respondent's expiations revealed that financial issues as the reason. Rests of the 6.5 percent affirmed distribution of work creates conflicts with local peoples. The finding of the study shows that among them, 6.1 percent respondents said that they go local Panchayat leader for resolution of their conflict. Panchayat leader is the administrative head of Bede community. While 33.3 percent respondents supposed that they mutually negotiate to resolve conflict and rests 4.8 percent respondents go to the police station, when local Panchayat transfer case to the police station and in case of severity only they go to the police station, otherwise in maximum cases Panchayat leader handle all types of conflicts between them.

\section{Cultural Practices, Exclusion, and Threats}

Bede people are small racial minority groups, so their cultural uniqueness adds a different dimension in cultural diversified countries like Bangladesh. Their precedent generations lived in a boat and they also lead a nomadic life. They have 
their own culture related to river, boat, snake, and nomadism. Due to river drying and loss of professional popularity, they want to settle themselves permanently. But when they started to live permanently, their culture (language, festivals, religious beliefs, clothing, entertainment, food habit, education, profession etc.) has been changing day by day. Around 80 percent of the total respondents affirmed that they have their own culture and rests 20 percent respondents claimed that they do not have their own culture. Their culture is different from the mainstream culture of Bangladesh. Around 73.8 percent respondents said that they have their own language that differentiates their culture from our national culture. While 26.2 percent respondents affirmed that they also have their own festival programs and some occasional festivals in where all Bede people Dhaka City be gathered in one place. If they all are Muslims, their religious belief matches with mainstream Muslim society. They celebrate all Muslim rituals like Eid-Ul-Fitr, Eid-Ul-Azha, Lailatul Quadr and others. They fast in Ramadan and give Kurbani in Eid-Ul-Azha. So, it is evident that they try to lead their life in accordance with Islamic Sariah. Savar called the capital of Bede community, and all Bede peoples are gathered at Savar in the festival of Eid-Ul-Azha per year. This meeting called Cowroshi, it is also their massive gathering and sign of their unity. In Cowroshi, they celebrate various programs, including dancing party, music, wedding ceremony etc. during their meeting. A Bede woman named Afroja Khatun (age 45 years old) said that:

Our massive gathering or festival (called Chowroshi) has special three days, among those special three days, first day, includes cultural programs (singing, dancing, sports etc.), Second day, includes judicial resolution and third day also includes cultural programs. Those days are always having a great traction for us because we all gather in one place and meet a lot of relatives. Around 20-25 wedding programs are held at those times, one wedding programs has been held after 1-2 days later again another wedding ceremony will be held. Sometimes these wedding programs continue through 2-3 months. Because people went to several districts and live in the tent surrounding a small place temporarily for earning in where they cannot arrange any wedding programs. So, they prefer to celebrate the marriage ceremony of their sons and daughters in Cowroshi. (Case study 5) 
Figure 3: Reasons behind cultural change of the respondents $(n=60)$

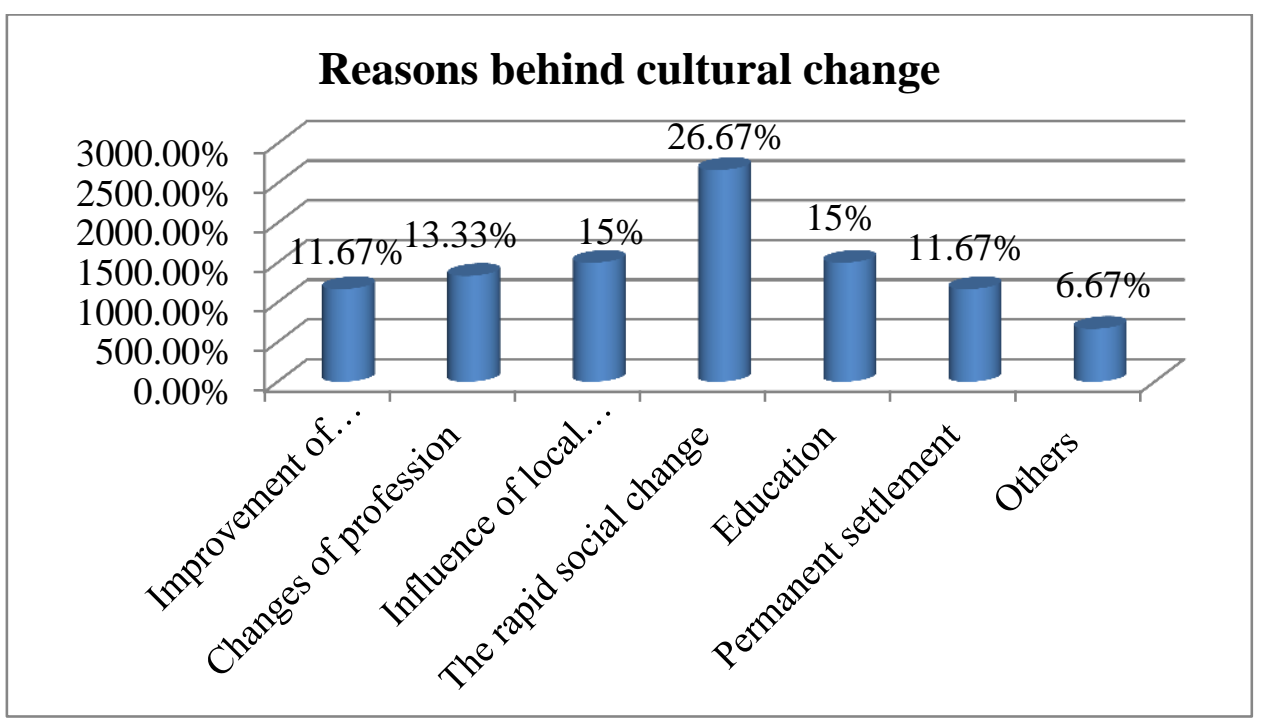

Source: Field survey 2020

In this study Figure 3 represent that 26.67 percent respondents said that the rapid social and cultural change due to urbanization and industrialization as the reason. Then 15 percent respondents explained that education works as a big factor of cultural change. Again, 13.33percent respondents revealed that changes of occupation also worked behind their cultural change. On the other hand, 11.67 percent respondents exposed that their settlement freed them from their nomadic life, their nomadic life was surrounded by some nomadic culture that has been changed with their permanent settlement and again 11.67 percent respondents claimed the improvement of information and communication technology has caused the changes of culture. Technology has brought about the great changes in culture of our whole society, Bede peoples are not exception. Meanwhile, 15 percent respondents said that due to permanent settlement they can come close to the local peoples, cultural practices of local peoples influence their cultural change and rests 6.67percentrespondents supposed that they have other causes for their cultural change.

A Bede woman named Alima Khatun (age 42 years) said:

We have forgotten our own language due to lack of practice. We use Bengali language as our main language instead of using our own ("Thet or Ther", language). We only use our own language to communicate with people in our 
own community. But through the passage of time now we prefer to use Bengali language and our children cannot speak our own language (Case study 6).

\section{Political involvement, Exclusion, and Vulnerability}

As Bede people also the Citizen of Bangladesh, patriotism is seen in their activities but most of the causes they are excluded from their political rights. The study represents that a small number, 13.3 percent of the respondents ensured that they have direct political involvement with various parties in Bangladesh. But rests a great segment of people 86.7 percent explained that they have no involvement in the politics of Bangladesh. The study also indicates that 71.67 percent (a major portion) of the total respondents agreed that they have a national identification number as an evidence of Bangladeshi citizen. But 28.33 percent respondents said that they have no national identification number due to some reasons. In where each 25 percent respondents, respectively explained having no right of franchise, unconsciousness, lack of political knowledge, have no permanent address as reasons behind their not enlistment of name in the list of Bangladeshi citizens. Bede people can give vote and stand in elections. Data shows that 75 percent respondents agreed that they give vote in elections. But 25 percent respondents said that they do not give a vote, from them, some do not give a vote despite having NID card, some do not give vote because they below 18 years old. From them 54.7 percent respondents narrated that they give vote in national elections; 38.7 percent respondents give vote in Paurashava election and 6.7 percent give vote in Union Parishad elections.

\section{Conclusion \& Recommendations}

From the foregoing discussion, it may conclude that the concept of social exclusion is a process of blocking the development of the marginalized communities disintegrating people and communities into mainstream of development, with a series of institutionalized social systems. So, Bede community faces many complexes and overlapping forms of discrimination like social, economic, political, religious, and cultural affecting all aspects of their personal and public lives. The present study revealed that the most people of the Bede community of Bangladesh live a substandard life deprived of most economic and social facilities of modern living. Moreover, Bede people are losing the demand of their traditional economic activities due to rapid social change. Some of them continue their traditional profession for survival due to 
lack of alternative means of income. Bede people have their own culture despite changing, but their cultural values and practices are not accepted with proper values in mainstream society, they face exclusion and discrimination due to cultural differences. The GO's and NGO's of Bangladesh should introduce both technical and general education to all Bede peoples in our country and should take steps so that efficient people from Bede community can get various government or non-government jobs and other economic facilities like SME loan or business opportunities. Female Bede should be trained up for making different types of handicrafts, poultry, and large animal farming, gardening, and vegetation. The government of Bangladesh should introduce one stop service programs for betterment of the Bede community in socio-economy spheres in Bangladesh.

\section{Reference}

Akter, Z., \& Kalam, D. A. (n.d.). Access to urban basic services of the people living in urban poverty: A case study of Bede community in Savar Municipality. Retrieved from https://www.bip.org.bd/SharingFiles/journal_book/20181204072956.pdf (Accessed on August 18, 2020).

Amin, M. N. (2015). An impact assessment of the trend of the life patterns of nomadic Bede Community in South-Western part of Bangladesh: A Sociological Analysis (Unpublished Masters thesis), Bangabandhu Sheikh Mujibur Rahman Science \& Technology University, Gopalganj, Bangladesh. Retrieved from https://www.researchgate.net/publication/ 316351827_An_Impact_Assessment_of_the_Trend_of_the_Life_Patterns_of_Nomadic_Bede _Community_in_South-Western_Part_of_Bangladesh_A_Sociological_Analysis (Accessed on November 19, 2020).

Arefeen, H. K. S. (1992). Sub-culture: Society of Bangladesh. Samaj Nirikhan,46(1),14-19.

Dalton, E. T. (1978). Tribal history of eastern India. New Delhi, India: Cosmo Publications.

Das, B. (2013). Rough Sailing for Bangladesh River-gypsies. Al Jazeera. Retrieved From http://www.aljazeera.com/indepth/features/2013/01/201312181138776540.html (Accessed on December 5, 2020).

Hossain, T. M., Miajee, E. Z. U. N., Khatun, A. M., \& Rahmatullah, M. (2010). A preliminary study of the health management practices of the Bede Community of Savar, Bangladesh and some of their ethnomedicinal formulations. American-Eurasian Journal of Sustainable Agriculture, 4(2), 136-146.

Islam, S. (2018, March 30). Dissecting the nomadic lifestyle of 'Bede' community, The Daily Sun, p. 3 Retrieved from https://www.daily-sun.com/printversion/details/298572/Dissecting-TheNomadic-Lifestyle-Of-Bede-Community (Accessed on December 5, 2020).

Jordan, B. (1996). A Theory of Poverty and Social Exclusion. Cambridge, UK: Blackwell Publishers Inc.

Kabeer, N. (2006). Social Exclusion and the MDGs: The challenge of 'Durable Inequalities' in the Asian Context. Institute of Development Studies Bulletin 37(3), 68-78. DOI:10.1111/j.17595436.2006.tb00270.x 
Maksud, A. K. M. (2002). Prospective and Possible Interventions and Potentials for Sustainable Development. Dhaka: Grameen Trust.

Maksud, A. K. M., \& Rasul, I. (2006). The nomadic Bede community and their mobile school program. Dhaka, Bangladesh: Grambangla Unnayan Committee.

Rahman, M. M. (2016, May 26). River Gypsies. Financial Express, p. 26. Retrieved from https://thefinancialexpress.com.bd/public/print/river-gypsies (Accessed on January 2, 2021).

Sarkara, K. C., Rahmanb, M., \& Saha, K. S. (2013). The Vanishing People and Vanishing Community: A Case Study in Bangladesh. International Journal of Sciences: Basic and Applied Research (IJSBAR), 12(1), 182-188.

Sen, A. (2000). Social Exclusion: Concept, Application and Scrutiny. Manila, Philippines: Asian Development Bank.

Shawon, R. A. R., \& Rabbi, E. M. (2017). Present social awareness and economic condition of nomadic Bede Community at Narayanganj District in Bangladesh. American Journal of Rural Development,5(4), 106-109. doi: 10.12691/ajrd-5-4-3 